for folate deficiency to become overtly manifest. ${ }^{4}$ We must, therefore, assume the existence of an aggravating factor which could cause a longstanding depletion of folate in this infant. The marginally low red blood cell folate concentration with incipient haematologic manifestations of folate deficiency in the mother cannot by itself be regarded as the cause of folate deficiency in her infant. 5

Our patient's mother had taken an oestrogenprogestin oral contraceptive regularly since her baby was 3 months old; these hormones are excreted in breast milk, and may impair folate absorption in the gut of the infant. A rapidly growing, fully breast fed baby may thus be deprived of his barely adequate folate input, and the stage is set for frank folate deficiency. This sequence of events may explain the development of severe folate deficiency in our patient. There are a good number of published reports on the relation between oral contraception and folate deficiency, but the association of oral contraception in the lactating mother and folate deficiency in her infant is presented here for the first time.

'Contraceptive pills with estrogen/progesterone' are listed among the drugs that are 'usually compat- ible with breast feeding' ${ }^{6}$ With the present day trend towards prolonged breast feeding, the concurrent use of oral contraceptives is likely to become more prevalent. Our report points out a potential hazard of maternal oral contraception to the breast fed infant.

\section{References}

'Barone C. Megaloblastic anemia due to folic acid deficiency after oral contraceptives. Haematologica (Pavia) 1979;64:190-5.

2 Dallman PR. Megaloblastic anemia: folate deficiency. In: Nathan DG, Oski FA, eds. Hematology of infancy and childhood. Philadelphia: WB Saunders, 1974:126-31.

${ }^{3}$ Hoffbrand AV, Necheles TF. Mechanisms of folate deficiency in patients receiving phenytoin. Lancet 1968;ii:528-30.

4 Herbert V. Experimental nutritional folate deficiency in man. Trans Assoc Am Physicians 1962;75:307-20.

5 Metz J. Folate deficiency conditioned by lactation. Am J Clin Nutr 1970;23:843-7.

- American Academy of Pediatrics: Committec on Drugs. The transfer of drugs and other chemicals into human milk. Pediatrics 1983;72:375-83.

Correspondence to Professor Moshe Berant, Department of Pediatrics 'B', Rambam Medical Center, Haifa 35254, Israel.

Received 24 July 1985

\title{
Should hepatitis B surface antigen positive mothers breast feed?
}

\author{
M DE MARTINO, C APPENDINO, M RESTI, M E ROSSI, A T MUCCIOLI, AND A VIERUCCI \\ Department of Paediatrics, Division of Clinical Immunology, University of Florence, Italy
}

SUMMARY Breast fed infants may be at greater risk of mother to infant hepatitis B virus infection compared with formula fed infants. We studied 85 infants born to 84 hepatitis B surface antigen positive mothers (only two of whom were hepatitis $\mathrm{B}$ e positive), and who had received immunisation against hepatitis $B$ virus. Our results indicate that breast feeding does not increase the risk of developing hepatitis B virus infection in infants born to these mothers if immunisation is carried out.

A vaccine against hepatitis $B$ virus is now available, and infants born to carrier mothers are one of the groups with immunisation priority as perinatal infection frequently results in the carrier status. ${ }^{1-3}$ Previous studies have shown that this vaccine is safe and effective in these infants ${ }^{4}$ however, whether the efficacy of the vaccine differs in breast and formula fed infants born to infected mothers is not known. This is possible as breast feeding may be a mechanism for mother to infant transmission. ${ }^{2} 56$ In this study we show that passive-active immunisation allows infants born to mothers who are hepatitis B virus surface antigen positive, hepatitis $B$ e negative to be breast fed without any added risk.

\section{Materials and methods}

Mothers. Eighty five infants born to 84 asymptomatic mothers who were hepatitis B surface antigen positive on routine prenatal screening were studied. The presence of hepatitis B surface antigen was detected in mothers' sera in two occasions, two months apart. In addition hepatitis B e antigen and antibodies and hepatitis B core antibodies were investigated.

Infants. The term infants studied ( 47 boys and 38 girls) were all born after a normal pregnancy and 
had a birthweight within the normal range (mean $3.12 \mathrm{~g}$ ). During the study no medication was given (except a multivitamin mixture), but the infants were vaccinated against polio, tetanus, and diphtheria. Mothers decided whether to breast feed or not. Twenty two infants ( 12 boys and 10 girls) were breast fed, and 63 ( 35 boys and 28 girls) were fed on a commercial formula.

Vaccine. The vaccine used is composed of $5 \mu \mathrm{g} / \mathrm{ml}$ of purified hepatitis $B$ surface antigen inactivated with formaldehyde and with aluminium hydroxide as adjuvant (Hevac B, Institute Pasteur, Paris).

Conduct of the trial. Within 8 hours of birth, babies were given an intramuscular injection $(0.5 \mathrm{ml} / \mathrm{kg})$ of immunoglobulins containing hepatitis B surface antigen, $100 \mathrm{IU} / \mathrm{ml}$ (hepatitis $B$ immune globulinHBIg-Biagini, Italy). Active immunisation was carried out by two injections of vaccine $(1 \mathrm{ml}$ subcutaneously) at age 2 and 4 months. A booster injection was administered nine months after the first dose. Blood samples were taken immediately before each of the first two injections, two and five months after the second injection, and one month after the third injection. The infants were visited monthly throughout the trial period, and the parents were asked to note any side effects. All parents had given informed consent. Strict adherence to the immunisation schedule was maintained, and compliance with follow up was excellent since none of the infants dropped out.

Laboratory methods. A radioimmunoassay was used to detect hepatitis B surface antigen and antibodies, hepatitis B e and antibodies, and hepatitis B core antibodies (AUSRIA, AUSAB, HBe, anti-HBe, and CORAB, respectively; Abbott Lab, USA). Hepatitis B surface antibody titres were measured in $\mathrm{mIU} / \mathrm{ml}$, and we considered positive the sera containing more than $0.7 \mathrm{mIU}-\mathrm{ml}$. This value was used to evaluate seroconversions. Alanine amino transferase and aminoaspartate transaminase were determined by using standard methods.

\section{Results}

Hepatitis B virus markers in mothers' sera. All the mothers were positive hepatitis B surface antigen and hepatitis B core antibodies. Hepatitis B e antigen was detected in only two mothers $(2 \cdot 3 \%)$, but antibodies were present in the remaining 82 women. One of two mothers positive for hepatitis $B$ e decided to breast feed her infant.

Immunogenicity and efficacy of the vaccine. As
Table Immunogenicity and efficacy of hepatitis $B$ vaccine in infants born to hepatitis $B$ surface antigen positive mothers

\begin{tabular}{llll}
\hline & $\begin{array}{l}\text { Overall results } \\
(n=85)\end{array}$ & $\begin{array}{l}\text { Breast fed } \\
\text { infants }(n=22)\end{array}$ & $\begin{array}{l}\text { Formula fed } \\
\text { infants }(n=63)\end{array}$ \\
\hline $\begin{array}{l}\text { Infants who } \\
\text { seroconverted }\end{array}$ & $\begin{array}{l}82 \\
(96 \cdot 5 \%)\end{array}$ & $\begin{array}{l}21 \\
(95 \cdot 4 \%)\end{array}$ & $\begin{array}{l}61 \\
(96 \cdot 8 \%)\end{array}$ \\
$\begin{array}{c}\text { Hepatitis B virus } \\
\text { infections }\end{array}$ & None & None & None \\
\hline
\end{tabular}

shown in the Table, a high percentage of infants seroconverted after the booster dose. No significant difference was observed between breast and formula fed infants. In no case was hepatitis B surface antigen detected during the trial period (finding of hepatitis B core antibodies was not considered important as these antibodies might have been due to passive immunisation of maternal origin). In addition, in no case was an abnormal increase in transaminase activities observed.

Side effects. No serious side effects were observed. On 11 occasions a small swelling at the site of injection or low grade fever, or both were reported, without any difference between the breast or formula fed infants. These side effects were probably the result of the aluminium hydroxide adjuvant in the vaccine.

\section{Discussion}

Babies born to infected mothers are at high risk of hepatitis $B$ virus infection. ${ }^{1-4}$ These babies are rarely exposed to infection in utero but this occurs more frequently during labour and delivery. ${ }^{1-4}$ Intimate maternal exposure may subsequently lead to transmission and it has been suggested that breast feeding may play a role in post partum infections. ${ }^{2} 5$ Our study confirms previous reports indicating that hepatitis $B$ virus vaccine is effective in infants born to hepatitis B surface antigen positive mothers. ${ }^{4} \mathrm{We}$ did not consider it ethically justified to randomise infants into a placebo group, since passive-active prophylaxis is known to prevent perinatal transmission. We did not, however, detect any signs of infection among 85 infants followed up for one year, whereas without any prophylaxis a considerable number of these infants have been shown to become carriers in the first years of life..$^{2-4}$ The number of hepatitis B e positive mothers was low in our study compared with others, ${ }^{2-4}$ and the presence of hepatitis $\mathrm{B}$ e positivity is considered the major determinant in mother to infant transmission of 
infection. ${ }^{2} 3$ Perinatal transmission, however, occurs in up to $30 \%$ of infants born to Hepatitis B e negative mothers. ${ }^{2} 3$

Our main finding is that by virtue of passive-active immunisation, breast fed infants are not at higher risk of contracting infection than formula fed infants. The possibility that hepatitis $B$ virus is present in breast milk is a controversial point, ${ }^{1} 25$ but it is beyond doubt that the virus may be ingested through blood or serum exuding from cracked nipples, ${ }^{6}$ which is a common occurrence, and it was therefore suggested that breast feeding of infants born to hepatitis B surface antigen positive mothers should be avoided. ${ }^{2}{ }^{6} \mathrm{We}$ suggest, however, that passive-active immunisation allows these infants to enjoy breast feeding, the nutritional, immunological, and psychological advantages of which are well known. In addition, breast feeding may help to lessen the guilt usually felt by these mothers.

Since mothers who are hepatitis B e positive are most infective, these conclusions may apply only in populations with low percentages of these mothers. Moreover, it is undoubtedly true that breast fed infants who do not seroconvert (less than $5 \%$ ) may remain at high risk from contracting infection, especially when their mothers are hepatitis $\mathrm{B}$ e positive. ${ }^{2} 3$

This work was partly supported by the Italian Consiglio Nazionale delle ricerche (Grant 83.02125.04).

\section{References \\ 1 Beasley RP, Stevens CE, Shiao IS, Meng HC. Evidence against breast-feeding as a mechanism for vertical transmission of hepatitis B. Lancet 1975;ii:740-1. \\ 2 Lee AKY, Ip HMH, Wong VCW. Mechanisms of maternal- fetal transmission of hepatitis B virus. J Infect Dis 1978;138: 668-71. \\ ${ }^{3}$ Beasley RP, Hwang LY. Postnatal infectivity of hepatitis B surface antigen-carrier mothers. $J$ Infect Dis 1983;147:185-90. \\ ${ }^{4}$ Wong CVW, Ip HMH, Reesink HW, et al. Prevention of the HBsAg carrier state in newborn infants of mothers who are chronic carriers of $\mathrm{HBsAg}$ and $\mathrm{HBeAg}$ by administration of hepatitis-B vaccine and hepatitis-B immunoglobulin. Double- blind randomised placebo-controlled study. Lancet $1984 ; \mathbf{i}$ 921-6. \\ 5 Boxall EH. Breast-feeding and hepatitis B. Lancet 1975;ii:979. \\ ${ }^{6}$ Krugman S. Vertical transmission of hepatitis B and breast- feeding. Lancet 1975;ii:916.}

Correspondence to Professor A Vierucci, Department of Paediatrics, Division of Clinical Immunology, A Meyer University Hospital, via Luca Giordano 13, I-50132 Florence, Italy.

Received 15 May 1985

\title{
Urinary kallikrein excretion in children of parents with essential hypertension
}

\author{
M UCHIYAMA, T OTSUKA, AND K SAKAI \\ Department of Paediatrics, Niigata University School of Medicine, Japan
}

SUMMARY Twelve hour urinary kallikrein excretion was measured in 18 healthy children of parents with essential hypertension and in 47 healthy children of parents without this disorder. No statistically significant difference was observed between the two groups of children.

Several investigations conducted in recent years have suggested that the kallikrein-kinin system has a role in a wide range of physiopathological processes. Clinical research originally concentrated on hypertensive conditions because of the very potent pharmacological action of kinins on vascular smooth muscle. It has been suggested that this system may regulate the control of blood pressure and circulatory homeostasis. Low urinary kallikrein excretion may be a pathogenetic factor in essential hyperten- sion in adults, ${ }^{1}$ and familial aggregation of urinary kallikrein values has been reported. ${ }^{2}$

The study of urinary kallikrein excretion in children is therefore important in elucidating the mechansim of the development of essential hypertension in later life. The aim of the present study was to investigate whether children who have parents with essential hypertension have lower urinary kallikrein excretion than control children.

\section{Subjects and methods}

Sixty five healthy normotensive children aged 7 to 15 years, from different families, were studied in the outpatient department at Niigata University Medical Hospital. Children with organic diseases were excluded from this study. A 12 hour overnight urine specimen was collected, and aliquots were stored at $-20^{\circ} \mathrm{C}$ until assay. Urinary kallikrein was estimated 